lysiert wie durch Lysozym in entsprechender Konzentration (Tab. 1).

\section{Diskussion}

Die Reindarstellung des von $\mathrm{T}_{2}$-infizierten $E$. coli B-Zellen in beträchtlicher Menge synthetisierten, lytischen Enzyms erweist sich als technisch relativ einfach, so daß das Sammeln genügender Mengen freien Enzyms für weitere Untersuchungen kein Problem ist.

In bezug auf die Ergiebigkeit des Ausgangsmaterials gestaltet sich die Lage erheblich ungünstiger bei der Gewinnung des entsprechenden, an T2-Teilchen gebundenen Enzyms. Dessen Präparierung verläuft zwar im wesentlichen nach dem hier beschriebenen Verfahren, das tatsächlich zunächst hierfür ausgearbeitet wurde, und auch seine Freisetzung aus T2-Teilchen ist nicht schwierig ${ }^{14,15}$, aber die erzielten Ausbeuten reichten noch nicht aus, um einen wirklich detaillierten Vergleich mit dem freien Enzym zu erlauben.

Wir konnten zwar zeigen, daß beide Enzyme das gleiche Substrat, eine bestimmte Schicht der ColiZellwand ${ }^{16}$, hydrolytisch angreifen und es in die gleichen Bestandteile zerlegen ${ }^{17}$, daß sie in dieser Beziehung wiederum mit Lysozym aus Eiklar übereinstimmen und somit ebenfalls als Lysozyme zu bezeichnen sind. Auch die besondere Rolle, die jedes von ihnen bei der Ingangsetzung bzw. Beendigung eines Vermehrungszyklus des T2-Phagen zu spielen hat, wurde verständlich gemacht ${ }^{21}$. Ein noch eingehenderer, insbesondere struktureller Vergleich wäre aber erwünscht, um weitere, sehr interessante Fragen beantworten zu können.

Um nur eine davon herauszugreifen: man wüßte gern, ob das in T2-Teilchen eingebaute, lytische Enzym einem großen, intrazellulären Pool von Enzym entnommen wird, dessen unverbrauchter Überschuß die Lyse der Zelle besorgt und dann als freies Enzym im Lysat erscheint, oder ob das teilchengebundene Enzym vielleicht keineswegs aus einem solchen Pool geschöpft, sondern nur in situ synthetisiert werden kann, d. h. an Ort und Stelle dort, wo jedes T2-Teilchen für sich den sogenannten Reifungsprozeß durchläuft. Dies wäre zwar nicht sehr ökonomisch, weil dann tatsächlich zwei unabhängige Synthesemechanismen von der infizierten Zelle aufgebaut werden müßten - einer für freies und einer für gebundenes Enzym -, obwohl im Grunde nur ein Enzym gebraucht wird, soweit das anzugreifende Substrat in Betracht steht. Womöglich ist aber nur dieser unökonomische Weg gangbar, und dann müßte man erwarten, daß die beiden Enzyme zwar funktionell, aber nicht strukturell übereinstimmen. Die schon erwähnten Befunde von Murphy ${ }^{6}$ an einem anderen System scheinen uns in diesem Sinne zu deuten.

Herrn Dr. K. Wagner sind wir für die Durchführung und Auswertung der Ultrazentrifugation, Frl. K. VoLL für ihre zuverlässige Hilfe bei der Herstellung von T2Lysaten zu großem Dank verpflichtet.

\title{
Uber die Geschwindigkeit der Protein-Synthese in kernlosen und kernhaltigen Zellen von Acetabularia*
}

\author{
Von H. Clauss und G. Werz \\ Aus dem Max-Planck-Institut für Meeresbiologie, Wilhelmshaven (Abt. HäмmerLing) \\ (Z. Naturforschg. 16 b, 162-165 [1961] ; eingegangen am 23. Dezember 1960)

\begin{abstract}
Comparing nucleate and enucleated cells of Acetabularia mediterranea and A. crenulata, the question was reexamined whether or not there is a temporary stimulation of protein synthesis in enucleated cells as reported by BRACHET and coworkers. The data presented here clearly show that there is no higher protein synthesis in enucleated cells than in nucleate ones: The rate of protein formation of enucleated cells is at most equal to that of nucleate cells during the first time following enucleation. It is concluded, that there is no inhibitory effect of the nucleus on protein synthesis.
\end{abstract}

Aus ihren Proteinbestimmungen an kernhaltigen und kernlosen Zellteilen von Acetabularia mediterranea schlossen Brachet und Mitarbb. ${ }^{1}$ (Abb. 9),

\footnotetext{
* Mit Unterstützung durch die Deutsche For schungsgemeinsch a ft.
}

daß bei kernlosen Zellteilen innerhalb der ersten 18 Tage nach ihrer Herstellung eine stärkere Proteinvermehrung erfolge als bei kernhaltigen, der

\footnotetext{
1 J. Brachet, H. Chantrenne u. F. Vanderhaeghe, Biochim. biophysica Acta [Amsterdam] 18,544 [1955], Abb. 9.
} 
Kern also einen hemmenden Einfluß auf die ProteinSynthese ausübe. Befunde von VANDERHaEghe ${ }^{2}$, von Brachet und Mitarbb. ${ }^{1}$ (Abb. 8) selbst und von Clauss $^{3}$ an gleichen und anderen Entwicklungsstadien ergaben aber, daß bei den kernlosen Teilen auch während der ersten Versuchstage keine stärkere Protein-Synthese als bei den kernhaltigen erfolgt, sondern daß sie im besten Falle gleich ist. Mitunter liegt zwar die Syntheserate in den kernlosen, aus der Spitzenregion der Zelle stammenden Teilstükken etwas höher, ohne daß jedoch solche Unterschiede als signifikant angesehen werden können ${ }^{3}$.

Wir haben die Frage, ob hemmende Einflüsse des Zellkernes auf im Plasma ablaufende Prozesse einwirken wegen ihrer grundsätzlichen Bedeutung in weiteren Versuchen noch einmal aufgegriffen.

Bei unseren Untersuchungen wurden kernlose Zellen, denen nur die Rhizoide entfernt worden waren, mit kernhaltigen Zellen verglichen. Dadurch ist es am ehesten möglich, Aufschlüsse über das Verhalten beider Typen zu erhalten. Bei einem Vergleich von kernlosen aus der Apikalregion der Zellen stammenden Teilen mit dem übrigen Rest der Zelle - dem Basalteil nebst Rhizoid - wie er von BRAchet und Mitarbb. ${ }^{1}$ angestellt wurde, stellen sich, zumindest innerhalb der ersten Tage nach dem Zerschneiden der Zellen, unkontrollierbare Verhältnisse ein. Diese beruhen einerseits auf intrazellulären apikal-basalen Gradienten ${ }^{3-6}$ und hängen andererseits mit Restitutions-Prozessen des rhizoid-haltigen Basalstückes zusammen.

\section{Material und Methoden}

Eine Versuchsserie wurde mit Acetabularia mediterranea durchgeführt. In Übereinstimmung mit BRACHET und Mitarbb. wurden Zellen untersucht, die sich im Stadium „Hut in Anlage“ befanden (Hutdurchmesser kleiner als $0,5 \mathrm{~mm}$, Stiellängen der Zellen zwischen 28 und $32 \mathrm{~mm}$ ). Die kernlosen Teile wurden zunächst unmittelbar über dem Rhizoid mit einem Seidenfaden abgeschnürt, um ein Auslaufen der Zellen zu verhindern ${ }^{7}$. Danach wurde das Rhizoid unterhalb der Schlinge mit einer Iridektomieschere (nach W e cker) abgeschnitten. Nach einer Erholungspause von einem Tag in diffusem Licht wurde der Versuch begonnen (Tag 0) und im Abstand von jeweils 7 Tagen der Proteingehalt der Zellen bestimmt. Die einzelnen Meßpunkte sind Mittel-

2 F. Vanderhaeghe, Biochim. biophysica Acta [Amsterdam] 18, 544 [1955].

3 H. Clauss, Planta 52, 334 [1958].

4 H. Clauss u. K. Keck, Planta 52, 543 [1959].

5 G. Werz u. J. Hämmerling, Planta 53, 145 [1959]. werte aus 4 Einzelbestimmungen, die ihrerseits je 25 Teile umfassen. Es wurden zwei verschiedene Nachzuchten geprüft.

Eine zweite Versuchsserie wurde mit Acetabularia crenulata durchgeführt. Verwendet wurden Zellen, $20 \mathrm{~mm}$ lang, ohne Hut und Zellen, 30-35 mm lang, mit dem ersten „Hut in Anlage“. Die kernlosen Teile wurden durch einfache Amputation der Rhizoide hergestellt und nach 2 Tagen in diffusem Licht in den Versuch genommen ( $\mathrm{Tag} 0$ ). Die Bestimmungen erfolgten in 3 verschiedenen Serien aus 2 Nachzuchten. Die einzelnen Meßpunkte der Abbildungen sind Mittelwerte, die aus mindestens 4 Einzelbestimmungen an je 20 bis 30 Versuchsteilen pro Serie erhalten wurden.

Die Kultur der Versuchspflanzen erfolgte nach den Vorschriften von HämmerLing ${ }^{8}$ und Beth ${ }^{7}$.

Der Protein-N-Gehalt wurde im Anschluß an die Extraktion des löslichen Stickstoffes mit Trichloressigsäure (TCE) und der Lipoide nach $\mathrm{K}$ j eld a h l bestimmt ${ }^{3,9}$. Es sei darauf hingewiesen, daß bei diesem Verfahren auch andere TCE-unlösliche N-haltige Substanzen erfaßt werden, jedoch dürften dadurch die Ergebnisse nicht wesentlich beeinflußt werden.

Bei Acetabularia mediterranea wurden die Rhizoide der kernhaltigen Zellen vor der Protein-N-Bestimmung entfernt, bei Acetabularia crenulata mitgemessen.

\section{Ergebnisse}

1. Proteinvermehrung in ganzen kernhaltigen und kernlosen Zellen vo n Acetabularia mediterranea

Sowohl bei den kernhaltigen als auch bei den kernlosen Zellen wuchs nur der bereits angelegte Hut weiter (bis zu etwa 3,5 mm Durchmesser im Mittel bei kernlosen und $5,0 \mathrm{~mm}$ bei kernhaltigen Zellen; vgl. Abb. 3). Dabei nahm der Proteingehalt zu (Abb. 1 a und b). Eine in kernlosen Zellen vorübergehend höhere Proteinsynthese als in kernhaltigen konnte nicht nachgewiesen werden. Vielmehr stimmte die Zunahme innerhalb der ersten 14 Tage (Versuch a) bzw. 7 Tage (Versuch b) mit der kernhaltiger Zellen überein. Ab 21 Tagen (Versuch a) bzw. 14 Tagen (Versuch b) ist die Differenz zwischen kernhaltigen und kernlosen Zellen statistisch gesichert verschieden $(P \text {-Wert }<0,0027)^{10}$.

Wie in früheren Versuchen ${ }^{3}$ kommt auch hier die Protein-Synthese in kernlosen Teilen nach ca. 4 bis 5 Wochen wahrscheinlich zum Stillstand. Die Zunahme zwischen 35 und 42 bzw. 28 und 35 Tagen

${ }^{6}$ G. Werz, Planta 53, 502 [1959]; 55, 22 [1960]; 55, 38 [1960].

7 K. Beth, Z. Naturforschg. 8 b, 334 [1953].

8 J. Ḧ̈mmerling, Arch. Protistenkunde 97, 7 [1944].

9 G. Werz, Experientia [Basel] 13, 79 [1957].

10 K. Pätau, Biol. Zbl. 63, 152 [1943]. 


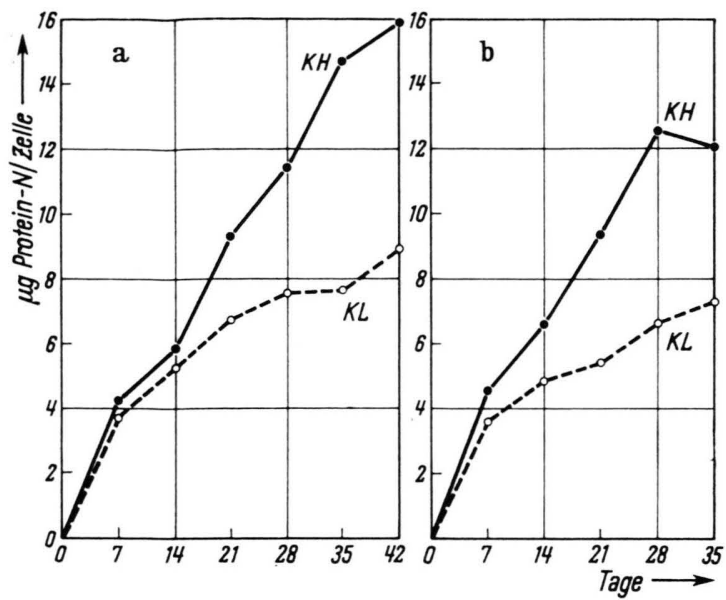

Abb. 1. Vergleich der Proteinsynthese von kernhaltigen und kernlosen ganzen Zellen von Acetabularia mediterranea. a) Nachzucht 1: Protein-N-Gehalt bei Versuchsbeginn $5,0 \mu \mathrm{g}$ / Zelle, sowohl der kernlosen als auch der kernhaltigen Zellen; die letzten nach Abtrennung der Rhizoide gemessen. b) Nachzucht 2: Protein-N-Gehalt bei Versuchsbeginn für kernhaltige und kernlose Zellen 5,75 $\mu \mathrm{g} /$ Zelle. .- $=$ kernhaltige Zellen $(\mathrm{KH}) ; \mathrm{O}---\mathrm{O}=$ kernlose Zellen (KL). Ausgangspflanzen: „Hut in Anlage“ bis 0,5 mm Durchmesser, Stiellängen 28-32 mm. Ordinate: Proteinstickstoff pro Zelle; Abszisse: Tage nach Versuchsbeginn.

ist nur schwach (Abb. 1 a, $P=0,045$ ), bzw. nicht gesichert (Abb. 1 b), $P=0,12$ ).

Die kernhaltigen Zellen vermehrten ihren Proteingehalt 4 Wochen (a) bzw. 5 Wochen (b) \pm linear, was sich bereits in früheren Untersuchungen zeigte $^{1,3,6}$. Das abrupte Aufhören der Proteinvermehrung in Nachzucht $b$ und das Nachlassen in Serie a dürfte auf das Eintreten der Cystenbildung zurückzuführen sein, mit der die Entwicklung der Zelle abgeschlossen wird.

Eine Senkung des Proteingehaltes der kernlosen Zellen nach Erreichen eines Maximalwertes wurde im Gegensatz zu den Befunden von Vanderhaeghe ${ }^{2}$, jedoch in Übereinstimmung mit den bisherigen Befunden aus dem hiesigen Institut nicht gefun$\operatorname{den}^{3,5,11}$.

2. Proteinvermehrung in ganzen kernhaltigen und kernlosen Zellen v o n Acetabularia crenulata

In keiner der drei geprüften Versuchsgruppen war bei kernlosen Zellen eine höhere Anfangsleistung festzustellen (Abb. $2 \mathrm{a}, \mathrm{b}$ und c). Bei Versuchsgruppe a war die Leistung der kernlosen Teile bis ca. 14 Tage nach Versuchsbeginn ebenso groß wie bei den kernhaltigen Zellen. Sie verhielt sich in ungefähr der gleichen Stärke sogar bis zur vierten

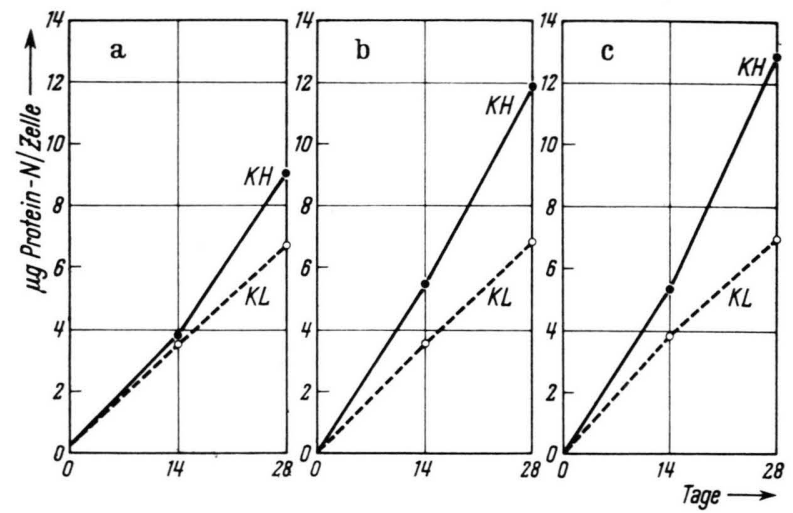

Abb. 2. Proteinvermehrung in kernhaltigen und kernlosen ganzen Zellen von Acetabularia crenulata. a) Nachzucht 1: Ausgangspflanzen $20 \mathrm{~mm}$ lang, ohne Hut; Protein-N-Gehalt zu Versuchsbeginn: bei kernhaltigen $8,3 \mu \mathrm{g} /$ Zelle, bei kernlosen $5,7 \mu \mathrm{g} /$ Zelle. b) Nachzucht 2, Serie 1: Ausgangspflanzen $30-35 \mathrm{~mm}$ lang, mit Hut in Anlage. Ausgangsprotein-NGehalt : 9,2 $\mu \mathrm{g} /$ Zelle bei kernhaltigen, $7,1 \mu \mathrm{g} /$ Zelle bei kernlosen; c) Nachzucht 2, Serie 2: 9,2 $\mu \mathrm{g} /$ Zelle bei kernhaltigen, $7,2 \mu \mathrm{g} /$ Zelle bei kernlosen. ·- $=$ kernhaltige Zellen (KH) ; O- - O = kernlose Zellen (KL). Bei den kernhaltigen Zellen erfolgten die Bestimmungen mit Rhizoid, daher die geringeren Ausgangswerte bei den kernlosen Zellen. Die 2. Serie (Abb. 2 c) wurde aus der gleichen Nachzucht zu einem späteren Zeitpunkt selektioniert. Ordinate: Proteinstickstoff pro Zelle; Abszisse: Tage nach Versuchsbeginn.

Woche, während die Synthese-Rate der kernhaltigen Zellen sich in dieser Zeit vielleicht etwas erhöhte. Auch bei den beiden anderen Versuchsgruppen (Abb. 2 b und c) blieb die Zunahme der kernlosen Zellen bis zum Versuchsende gleich, war hier aber von Anfang an niedriger als die der kernhaltigen Zellen. Die eine Serie der kernhaltigen Zellen scheint wiederum eine Andeutung einer Steigerung der Synthese-Rate vom 14. Tage ab zu zeigen. Eine Abnahme des Proteingehaltes bei den kernlosen Zellen wurde auch bei diesen Versuchen nicht beobachtet, nach 4 Wochen noch nicht einmal eine Tendenz zur Sistierung der Protein-Vermehrung.

\section{Diskussion}

Das gesamte, bisher vorliegende Material aus früheren $2,3,5,11$, den hier dargestellten sowie aus unveröffentlichten Untersuchungen zur Frage der Geschwindigkeit der Proteinsynthese bei Anwesenheit oder Fehlen des Zellkernes zeigt übereinstimmend keine Erhöhung der Proteinsynthese in kernlosen Zellen. Nur bei dem von Brachet und Mitarbb. ${ }^{1}$ untersuchten Material und bei diesem auch

11 J. Hämmerling, H. Clauss, K. Keck, G. Richter u. G. Werz, Exp. Cell Res. Suppl. 6, 210 [1958]. 
nur bei Verwendung der aus $1 / 3$ der Zellänge bestehenden kernhaltigen und $2 / 3$ der Zellänge bestehenden kernlosen Teilen aus der Apikalregion (diese im Stadium der beginnenden Hutbildung) wurde eine Erhöhung der Proteinsynthese in den kernlosen Teilen gefunden. Dieser Befund erweist sich nach unseren Untersuchungen als nicht reproduzierbar, auch dann nicht, wenn ganze Zellen und Zellen, an denen nur das Rhizoid entfernt worden war, im gleichen Entwicklungsstadium geprüft wurden. Unsere eigenen Untersuchungen sowie die von VANDERHAEGHE $^{2}$ und das zweite von Brachet und Mitarbb. ${ }^{1}$ geprüfte Stadium erstreckte sich auf verschiedene Nachzuchten und Altersstadien von $15-18 \mathrm{~mm}$ langen Pflanzen bis zu solchen mit Hut in Anlage. Der von Brachet und Mitarbb. ${ }^{1}$ mitgeteilte Fall bleibt eine Ausnahme, für dessen Ursache eine Erklärung nicht gegeben werden kann. Am ehesten könnte man noch daran denken, daß die Proteinzunahme der kernhaltigen Teile aus äußeren Gründen gehemmt war. Für die von Brachet und Mitarbb. ${ }^{1}$ gemachte generelle Annahme, die grundsätzliche Bedeutung hätte, daß nämlich der Kern in gewissen Entwicklungsstadien einen hemmenden Einfluß auf die Protein-Synthese ausübt, liegt kein Hinweis vor. BRACHET und Mitarbb. beziehen sich dabei auf eine Beobachtung von BETH ${ }^{12}$. Dieser hat bei einem bestimmten Entwicklungsstadium gefunden, daß bei einem Vergleich von ganzen kernhaltigen und kernlosen Zellen die Hutbildung bei den kernlosen Zellen früher einsetzte als bei den kernhaltigen. Als eine der hierfür möglichen Erklärungen wurde eine hemmende Wirkung des Kernes angenommen. Aber diese Möglichkeit hat BETH ${ }^{12}$ nur auf das Eintreten der Hutbildung bezogen; sie braucht sich nicht auf die Wuchsgeschwindigkeit und die Geschwindigkeit der Protein-Produktion zu beziehen ${ }^{13}$ (s. auch hier$\mathrm{zu}^{3}$ Abb. 2, $3 \mathrm{a}-\mathrm{c}, 5 \mathrm{a}-\mathrm{c}$ ). Werden ganze kernhaltige und kernlose Zellen verglichen, so ist sowohl die Protein-Synthese (Abb. $1 \mathrm{a}$ und b) als auch das

12 K. BETH, Z. Naturforschg. 8 b, 771 [1953].

$13 \mathrm{Da}$ die ablaufenden Prozesse viel komplizierter sind, ergeben spezielle Untersuchungen von H. Clauss (Naturwissenschaften, im Druck). Es konnte nachgewiesen werden, daß bei Eintritt der Hutbildung zu einer Neusynthese von Proteinen noch zusätzlich eine Neuverteilung der bereits vorhandenen Zellproteine hinzukommt, die sich in einer Abwanderung aus dem Stiel in den Hut äußert.

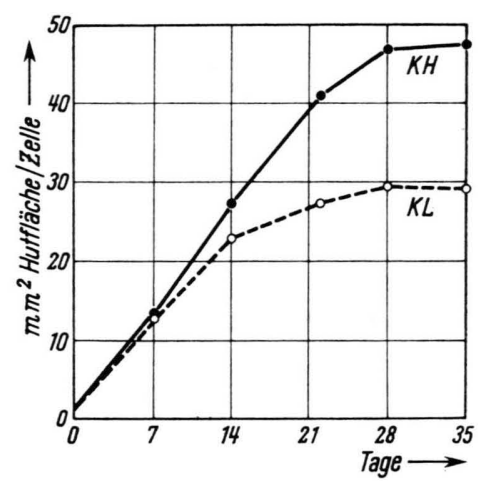

Abb. 3. Vergleich des Wuchsvermögens von kernhaltigen und kernlosen ganzen Zellen von Acetabularia mediterranea. Dasselbe Material wie Abb. 1 a. Ausgangspflanzen mit „Hut in Anlage“. Als Maß des Wachstums ist die Vergrößerung der Hutfläche angegeben (eine Streckung des Stiels findet zu diesem Zeitpunkt nicht mehr statt). Von den kernhaltigen Zellen hatten nach 35 Tagen $4 \%$, nach 42 Tagen $26 \%$ Cysten gebildet. $\cdot-=$ kernhaltige Zellen $(\mathrm{KH}) ; 0---0=$ kern-

lose Zellen (KL). Ordinate: Hutfläche pro Zelle in $\mathrm{mm}^{2}$. Abszisse: Tage nach Versuchsbeginn.

Wachstum (Abb. 3) in beiden Systemen zunächst gleich, um dann später bei den kernlosen Zellen abzunehmen. Auch aus diesem Grunde wäre eine Erhöhung der Protein-Produktion durch die Entfernung des Kernes überraschend.

Brachet und Mitarbb. ${ }^{1}$ haben angegeben, da $\beta$ sich in kernlosen Teilen auch der Ribose-Nucleinsäure(RNS)-Gehalt erhöhe. Hier schien eine gute Übereinstimmung darin zu bestehen, daß er ebenso wie der Proteingehalt anfänglich in den kernlosen Teilen schneller zunehmen sollte als in den kernhaltigen. Diese Übereinstimmung entfällt nach dem Vorstehenden nicht nur, weil die Protein-Synthese nicht erhöht wird, sondern auch deshalb, weil sich nach den Untersuchungen von RichteR ${ }^{14}$ gezeigt hat, $\mathrm{da} ß$ der RNS-Gehalt in kernlosen Teilen nicht zunimmt. Diese Ergebnisse sind inzwischen von anderer Seite unter Anwendung der gleichen oder anderer Methoden bestätigt worden ${ }^{15,16}$, darunter auch von Brachet selbst ${ }^{17}$.

14 G. Richter, Naturwissenschaften 44, 520 [1957] ; Biochim. biophysica Acta [Amsterdam] 34, 497 [1959].

15 H. NaOra, G. Richter u. H. NaOra, Exp. Cell Res, 16, 434 [1959].

16 H. G. Schweiger u. H. J. Bremer, Exp. Cell Research 20. 617 [1960]; Biochim. biophysica Acta [Amsterdam], im Druck.

17 H. Naora, H. Naora u. J. Brachet, J. gen. Physiol. 43, 1083 [1960]. 